\title{
NISSEN FUNDOPLICATION FOR THE TREATMENT OF GASTROESOPHAGEAL REFLUX DISEASE IN PATIENTS WITH CHAGAS DISEASE WITHOUT ACHALASIA
}

\author{
São Paulo, November $14^{\text {th }}, 2009$
}

Dear Sir:

Chagas disease (CD) is very prevalent in South America, with wellknown manifestations in the digestive system. CD esophagopathy leads to a clinical and manometric picture similar to idiopathic (primary) achalasia ${ }^{4}$. Although the treatment for CD esophagopathy is well established ${ }^{3}$, South American surgeons and gastroenterologists are sometimes faced with CD patients without esophageal involvement but with gastroesophageal reflux disease (GERD) complaints. Surgical therapy in these patients may be debatable due to the fear of deterioration of esophageal peristalsis over time and consequent dysphagia.

The present aim is to evaluate, in a multicenter and retrospective study, the outcomes of Chagasic patients without achalasia submitted to laparoscopic Nissen fundoplication for the treatment of GERD.

Between 1999 and 2009, six patients with CD without Chagasic esophagopathy (achalasia) underwent Nissen (total) fundoplication at three different institutions, all highly experienced in the treatment of CD. There were five females, mean age 61 (range 57-64) years.

CD was diagnosed based on positive serologic test for $\mathrm{CD}$ and/or typical manifestations of $\mathrm{CD}$ in other target organs (heart or colon). Primary clinical findings were heartburn in five patients $(83 \%)$, cough in one $(17 \%)$ and had mild dysphagia in one (17\%).

This study included the analysis of existing data with no subject intervention. No identifiers were used or sent to the coordinating center. Institutional review board submission was waived. Preoperative workup is summarized in Table 1.

All patients had been treated medically for GERD for at least six months prior to the operation and underwent a short-floppy laparoscopic Nissen fundoplication plus hiatoplasty. Short gastric vessels were divided in three patients $(50 \%)$ and one $(17 \%)$ had a hiatal mesh repair.

Patients were followed-up for a mean period of 57 (range 8-89) months. Postoperative complaints were dysphagia in one $(17 \%)$ and bloating in one $(17 \%)$.

The patient with postoperative dysphagia did not present dysphagia preoperatively but had complaint of dysphagia for solid foods after the operation. Repeated upper digestive endoscopy and esophagram were normal. Postoperative esophageal manometry disclosed an LES basal pressure of $13 \mathrm{mmHg}$ with normal relaxation and normal peristalsis of the esophageal body. The patients were treated conservatively. Tests
Table 1

Preoperative workup

\begin{tabular}{|c|c|c|}
\hline Test & Number of patients & Results \\
\hline \multicolumn{2}{|c|}{$\begin{array}{l}\text { Upper digestive } 6(100 \%) \\
\text { endoscopy }\end{array}$} & $\begin{array}{l}\text { Barrett's esophagus - } 1(17 \%) \\
\text { Hiatal hernia - } 2(33 \%)\end{array}$ \\
\hline $\begin{array}{l}\text { Esophageal } \\
\text { manometry }\end{array}$ & $6(100 \%)$ & $\begin{array}{l}\text { LES mean pressure } 8 \text { (range } \\
3-15 \text { ) mmHg } \\
\text { LES relaxation normal in all } \\
\text { cases } \\
\text { Mean esophageal body distal } \\
\text { pressure at } 3 \mathrm{~cm} \text { above the LES } \\
62 \text { (range } 35-93 \text { ) } \mathrm{mmHg} \text {. } \\
1(17 \%) \text { patient had } 30 \% \text { of } \\
\text { non-peristaltic (simultaneous) } \\
\text { waves, all other had normal } \\
\text { peristalsis. }\end{array}$ \\
\hline $\begin{array}{l}\text { Barium } \\
\text { esophagram }\end{array}$ & $4(67 \%)$ & $\begin{array}{l}\text { hiatal hernia - } 3(50 \%) \\
\text { gastroesophageal reflux - } 2 \\
(33 \%) \\
\text { Esophageal dilatation was not } \\
\text { observed. }\end{array}$ \\
\hline
\end{tabular}

LES - lower esophageal sphincter.

were not repeated in the postoperative period in the other patients due to the lack of symptoms.

Chagas disease is a systemic disease. Megacolon, heart disease and achalasia are the most common manifestations of the disease $\mathrm{e}^{4,10}$; however, megastomach ${ }^{9}$, enteropathy ${ }^{6}$, gallstones ${ }^{9}$, and cardiovascular autonomic function $^{11}$ have all been associated to $\mathrm{CD}$. The real incidence of the association of GERD and CD is unknown but it seems to be unexplainably low. GERD is rarely described in untreated patients and we were able to find only six patients operated on in a multicenter study encompassing four centers with a large volume of patients with CD.

Esophageal symptoms, motility disorders, and dilatation of the esophagus are present in nearly $10 \%$ of patients with $\mathrm{CD}^{8}$. Moreover, studies in patients with $\mathrm{CD}$ without esophageal complaints show that over $20 \%$ of the patients show some sort of manometric abnormality ${ }^{1}$. These findings make the wisdom of performing a total fundoplication in patients with GERD and CD questionable.

Manometric findings of Chagasic achalasia are similar to the ones of idiopathic achalasia: aperistalsis and non-relaxing lower esophageal 
PANTANALI, C.A.R.; HERBELLA, F.A.M.; HENRY, M.A.C.A.; AQUINO, J.L.B.; FARAH, J.F.M. \& DEL GRANDE, J.C. - Nissen fundoplication for the treatment of gastroesophageal reflux disease in patients with Chagas disease without achalasia. Rev. Inst. Med. Trop. Sao Paulo, 52(2):113-4, 2010.

sphincter ${ }^{4}$. Different from idiopathic achalasia, CD patients may present initially with a non-specific undetermined manometric picture with findings such as: simultaneous contractions, low amplitude contractions and failed lower esophageal sphincter relaxation ${ }^{1}$. Furthermore, some studies provided evidence of progression of peristaltic waves to aperistaltic in sequential manometries ${ }^{6}$. These patients in the undetermined phase of the disease may constitute an experimental model for the hypothesis that esophageal motility disorders progress from one type to another ${ }^{5}$. Our study was motivated by the fear of performing a total (Nissen) fundoplication in patients with CD due to the chance of progression to an esophageal dysmotility or even achalasia.

Our results show that Nissen fundoplication in patients with CD without Chagasic achalasia has excellent results in the majority of patients with an acceptable rate of dysphagia. The case of postoperative dysphagia probably has a different cause for the symptom, since manometry was normal. It must be emphasized that an adequate work-up is necessary in these patients. Esophageal function tests are mandatory, since patients with $\mathrm{CD}$ and dysphagia may not have esophageal aperistalsis ${ }^{2,6}$ and patients without dysphagia may have manometric disorders ${ }^{1}$. Furthermore, symptoms are unreliable as dysphagia may be a symptom of GERD and heartburn a symptom of achalasia. Obviously, this study has some limitations: (a) it is a very small retrospective series; (b) manometry and other tests were not repeated in the postoperative period since patients were asymptomatic, (c) tests were performed in different centers with different methods; and (d) the time of follow-up may be short.

We conclude that Nissen fundoplication is a safe method for the treatment of GERD in patients with CD without Chagasic achalasia.

Carlos A.R. PANTANALI, MD(1)

Fernando A. M. HERBELLA, MD(1)

Maria A. C. A. HENRY, MD(2)

Jose L. B. AQUINO, MD(3)

Jose Francisco Mattos FARAH, MD(4)

Jose C. DEL GRANDE, MD(1)

(1)Department of Surgery, Escola Paulista de Medicina, Federal University of São Paulo, São Paulo, SP, Brazil.

(2)Department of Surgery and Orthopedics,

State University of São Paulo, Botucatu, SP, Brazil. (3)Department of Surgery, Catholic University of Campinas, Campinas, SP, Brazil.

(4)Department of Surgery, Hospital do Servidor Público Estadual de São Paulo Francisco Morato de Oliveira, São Paulo, SP, Brazil.

Correspondence to: Dr. Fernando Herbella, Rua Diogo de Faria 1087, cj 301, 04037-003 São Paulo, SP, Brasil.

Phone/fax: 55-11-39267610. herbella.dcir@epm.br

\section{REFERENCES}

1. Dantas RO, Deghaide NH, Donadi EA. Esophageal manometric and radiologic findings in asymptomatic subjects with Chagas' disease. J Clin Gastroenterol. 1999;28:245-8.

2. Dantas RO. Dysphagia in patients with Chagas' disease. Dysphagia. 1998;13:53-7.

3. Herbella FA, Aquino JL, Stefani-Nakano S, Artifon EL, Sakai P, Crema E, et al. Treatment of achalasia: lessons learned with Chagas' disease. Dis Esophagus. 2008;21:461-7.

4. Herbella FA, Oliveira DR, Del Grande JC. Are idiopathic and Chagasic achalasia two different diseases? Dig Dis Sci. 2004;49:353-60.

5. Khatami SS, Khandwala F, Shay SS, Vaezi MF. Does diffuse esophageal spasm progress to achalasia? A prospective cohort study. Dig Dis Sci. 2005;50:1605-10.

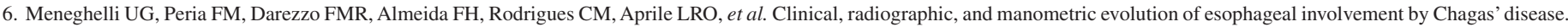
Dysphagia. 2005;20:40-5.

7. Meneghelli UG. Chagasic enteropathy. Rev Soc Bras Med Trop. 2004;37:252-60.

8. Oliveira RB, Troncon LEA, Dantas RO, Meneghelli UG. Gastrointestinal manifestations of Chagas' disease. Am J Gastroenterol. 1998;93:884-9.

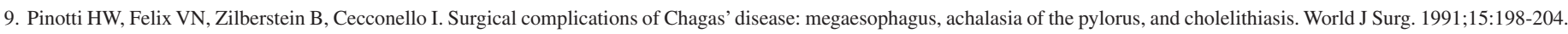

10. Teixeira AR, Nitz N, Guimaro MC, Gomes C, Santos-Buch CA. Chagas disease. Postgrad Med J. 2006;82(974):788-98.

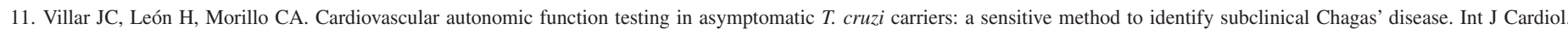
2004;93:189-95. 